University of Nebraska - Lincoln DigitalCommons@University of Nebraska - Lincoln

Publications, Agencies and Staff of the U.S.

Department of Commerce

U.S. Department of Commerce

2012

Estimating Precipitation from WSR-88D

Observations and Rain Gauge Data: Potential for

Drought Monitoring

GregoryJ. Story

National Weather Service

Follow this and additional works at: http:/ / digitalcommons.unl.edu/usdeptcommercepub

Story, Gregory J., "Estimating Precipitation from WSR-88D Observations and Rain Gauge Data: Potential for Drought Monitoring" (2012). Publications, Agencies and Staff of the U.S. Department of Commerce. 556.

http://digitalcommons.unl.edu/usdeptcommercepub/556

This Article is brought to you for free and open access by the U.S. Department of Commerce at DigitalCommons@University of Nebraska - Lincoln. It has been accepted for inclusion in Publications, Agencies and Staff of the U.S. Department of Commerce by an authorized administrator of

DigitalCommons@University of Nebraska - Lincoln. 
Published in Remote Sensing of Drought: Innovative Monitoring Approaches, edited by Brian D. Wardlow, Martha C. Anderson, \& James P. Verdin (CRC Press/Taylor \& Francis, 2012).

This chapter is a U.S. government work and is not subject to copyright in the United States.

Author:

\section{Gregory J. Story}

West Gulf River Forecast Center

National Weather Service

Fort Worth, Texas 


\title{
12 Estimating Precipitation from WSR-88D \\ Observations and Rain \\ Gauge Data \\ Potential for Drought Monitoring
}

\author{
Gregory J. Story
}

\section{CONTENTS}

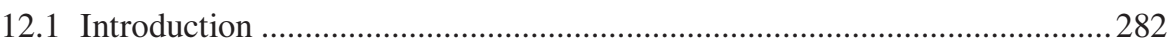

12.2 Past Efforts in Determining Mean Areal Precipitation................................283

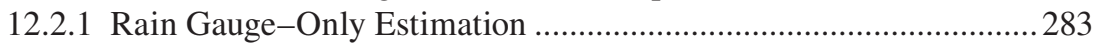

12.2.2 Radar Rainfall Estimation before the WSR-88D .............................283

12.3 Current Estimation of Precipitation............................................................284

12.3.1 Radar: The WSR-88D Precipitation Estimation Algorithm..............284

12.3.1.1 Problems with Radar-Based Precipitation Estimates ........285

12.3.1.2 Benefits of Radar-Based Precipitation Estimates .............. 291

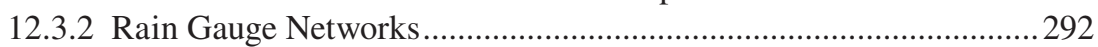

12.3.2.1 Near-Real-Time Gauges.....................................................292

12.3.2.2 Daily Reporting Gauges.................................................... 292

12.4 Radar-Based Multisensor Precipitation Estimator Precipitation

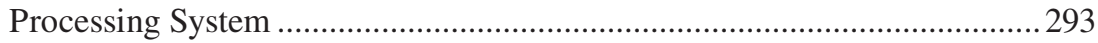

12.4.1 Three Stages of MPE Precipitation Processing ................................2294

12.4.1.1 Stage I of the MPE PPS .................................................... 294

12.4.1.2 Stage II of the MPE PPS ...................................................294

12.4.1.3 Stage III of the MPE PPS ………………………….........295

12.4.2 Q2, the Next-Generation QPE .......................................................296

12.4.3 Satellite Precipitation Estimates ........................................................296

12.4.4 Final Postanalysis Quality Control Technique .................................297

12.5 Drought Monitoring: How These Estimates Can Be Used

to Determine Current Locations of Drought ..................................................297 
12.5.1 NWS Southern Region Precipitation Analysis Project.....................297

12.5.2 Advanced Hydrologic Prediction Service.......................................299

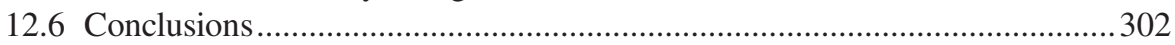

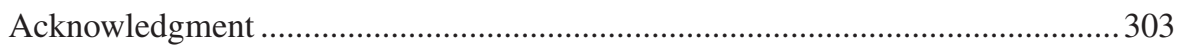

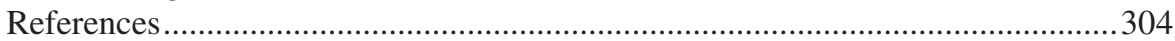

\subsection{INTRODUCTION}

Since its deployment, the precipitation estimates from the network of National Weather Service (NWS) Weather Surveillance Radars-1988 Doppler (WSR-88D) have become widely used. These precipitation estimates are used for the flash flood warning program at NWS Weather Forecast Offices (WFOs) and the hydrologic program at NWS River Forecast Centers (RFCs), and they also show potential as an input data set for drought monitoring. However, radar-based precipitation estimates can contain considerable error because of radar limitations such as range degradation and radar beam blockage or false precipitation estimates from anomalous propagation (AP) of the radar beam itself. Because of these errors, for operational applications, the RFCs adjust the WSR-88D precipitation estimates using a multisensor approach. The primary goal of this approach is to reduce both areal-mean and local bias errors in radar-derived precipitation by using rain gauge data so that the final estimate of rainfall is better than an estimate from a single sensor.

This chapter briefly discusses the past efforts for estimating mean areal precipitation (MAP). Although there are currently several radar and rain gauge estimation techniques, such as Process 3, Mountain Mapper, and Daily Quality Control (QC), this chapter will emphasize the Multisensor Precipitation Estimator (MPE) Precipitation Processing System (PPS). The challenges faced by the Hydrometeorological Analysis and Support (HAS) forecasters at RFCs to quality control all sources of precipitation data in the MPE program, including the WSR-88D estimates, will be discussed. The HAS forecaster must determine in real time if a particular radar is correctly estimating, overestimating, or underestimating precipitation and make adjustments within the MPE program so the proper amount of precipitation is determined. In this chapter, we discuss procedures used by the HAS forecasters to improve initial best estimates of precipitation using $24 \mathrm{~h}$ rain gauge data, achieving correlation coefficients greater than 0.85 . Finally, since several organizations are now using the output of MPE for deriving short- and long-term Standardized Precipitation Indices (SPIs), this chapter will discuss how spatially distributed estimates of precipitation can be used for drought monitoring.

The U.S. Drought Monitor (USDM), which is considered the current state-ofthe-art drought monitoring tool for the United States, is presently not designed for county-scale representations, yet its output is used by customers for critical decision making at this spatial scale. Thus, drought indicators are needed at the county and subcounty scale. The MPE estimates can be used as a "gold standard" precipitation product to compare with or validate other remote-sensing drought products, as long as the user understands the weaknesses of MPE. In the hands of a knowledgeable user, MPE provides information that no other existing drought tool can provide. With these products, we can look at detailed rainfall patterns and see how they correlate 
with evapotranspiration (ET) products across large areas, as well as identify localized areas of rainfall deficits over time. These data could also provide higher-resolution inputs for remote-sensing drought index formulations such as the Vegetation Drought Response Index (VegDRI) (Brown et al., 2008). VegDRI currently integrates SPI grids spatially interpolated from Applied Climate Information System (ACIS) gauge data, which characterize broadscale precipitation patterns but are often unrepresentative of county-scale level precipitation variations. Higher-spatial-resolution $4 \mathrm{~km} \mathrm{MPE}$ observations are now available to enhance these types of tools and support local-scale drought monitoring and early warning activities that have been identified as a priority by the recently established National Integrated Drought Information System (NIDIS).

\subsection{PAST EFFORTS IN DETERMINING MEAN AREAL PRECIPITATION}

This chapter briefly discusses some of the reasons why the WSR-88D does not always estimate precipitation accurately and explain how HAS forecasters use the MPE PPS to determine the accuracy of radar precipitation estimates, as well as highlight some known issues with traditional rain gauge data. But before we look at the current state of ground-based radar rainfall estimation, an examination of past estimation techniques will be presented to gain an appreciation of the current algorithms.

\subsubsection{Rain Gauge-Oniy Estimation}

Before MPE, the RFCs only used rain gauge data to calculate basin-averaged MAP, which is the average depth of precipitation over a specific area for a given time period. This led to timing and location errors in the identification of heavy rainfall events, especially in a highly convective environment where intense rainfall often occurs over small core areas. Precipitation estimates were generated from discrete rain gauge observations using the Thiessen polygon method. This method attempted to calculate MAP, allowing for a nonuniform distribution of gauges by providing a weighting factor for each gauge. In basins where no rain gauges existed, this method was forced to use rain gauges that were outside the basin in question for its calculation. Although gauge-only analyses exist for drought monitoring in the United States at the climate division scale (e.g., the 1 month accumulated precipitation product at http://www.wrcc.dri.edu/spi/spi.html), these products are noisy, particularly in the western United States where gauge density is sparse with only a few observations per climate division. And since older radar systems described in the next section did not have the computer algorithms necessary to produce MAP, RFCs had no choice but to use a rain gauge-only methodology.

\subsubsection{Radar Rainfall Estimation before the WSR-88D}

Early radar systems (WSR-57, WSR-74S, and WSR-74C) came on line in 1973 and were used through 1993, but meteorologists at that time used a very crude technique for determining rainfall rates. These early radar networks would show rainfall and 
storm intensities using digital video integrator and processor (D/VIP) levels. The D/VIP levels were based on a predetermined value of returned power called the equivalent reflectivity, Z. A lookup table was used to establish rainfall rates for each D/VIP level. Radar operators would place a digital grid over the planned position indicator (PPI) radar scope and manually write in a value ranging from 0 to 6 that represented the maximum D/VIP level in each grid cell. The rectangular grid cells are known as manually digitized radar (MDR) boxes, which are based on a subgrid of the Limited Fine Mesh (LFM) model. The spatial resolution of the MDR grid cell was approximately $40 \mathrm{~km}$. By contrast, the Hydrologic Rainfall Analysis Project (HRAP) grid now used by the WSR-88D has further improved the spatial resolution to $\sim 4 \mathrm{~km}$.

After the radar operators determined the maximum D/VIP level in each MDR box, they would transfer these values onto a paper overlay, which was usually a county boundary map. As an example, a D/VIP level of 5 meant the returned power from the echo had an equivalent reflectivity $\mathrm{Z}$ of between 50 and 57 decibels (dBZ). Next the operators would attempt to determine how much rain had accumulated. Using a reflectivity rainfall rate table, the hourly rainfall rate for this value would be found to be $4.5-7.1 \mathrm{in} . / \mathrm{h}$ in a convective environment. They would then visually inspect the D/VIP levels over the past few hours and add the D/VIP levels together for longer-term rainfall estimates for specific counties. Using these early methods, considerable guesswork and manual analysis was involved in using radar to determine the amount of rainfall.

\subsection{CURRENT ESTIMATION OF PRECIPITATION}

\subsubsection{Radar: The WSR-88D Precipitation Estimation Algorithm}

Estimates from radar have become the base product for deriving mean areal, basinaveraged precipitation within the NWS. A photograph of a typical WSR-88D station is shown in Figure 12.1. The precipitation algorithm in the WSR-88D radar product generator (RPG) is complex, and given all the factors involved in radar sampling and performance, such as proper radar calibration and assumptions regarding radio wave propagation through the atmosphere, errors in radar precipitation estimates often occur. The precipitation algorithm contains dozens of adaptable parameters that control its performance (Fulton et al., 1998), improving accuracy over earlier radar estimation methods (Pereira Fo et al., 1988). The algorithm itself consists of five main scientific processing components (or subalgorithms) and an external independent support function called the precipitation detection function (NWS/ROC, 1999). The five scientific subalgorithms are (1) preprocessing, (2) determination of rainfall rate, (3) determination of rainfall accumulation, (4) rainfall adjustment, and (5) generation of precipitation products. The five subalgorithms are executed in sequence as long as the precipitation detection function determines that rain is occurring anywhere within a $230 \mathrm{~km}$ radius of the radar, which is referred to as the radar umbrella.

Once precipitation is detected, the first subalgorithm is executed: The base reflectivity data go through the preprocessing stage, which includes a quality control step that corrects for beam blockage using a terrain-based hybrid scan (O'Bannon, 1997) and checks for AP and biscan maximization (see Fulton et al., 1998 for more details). 


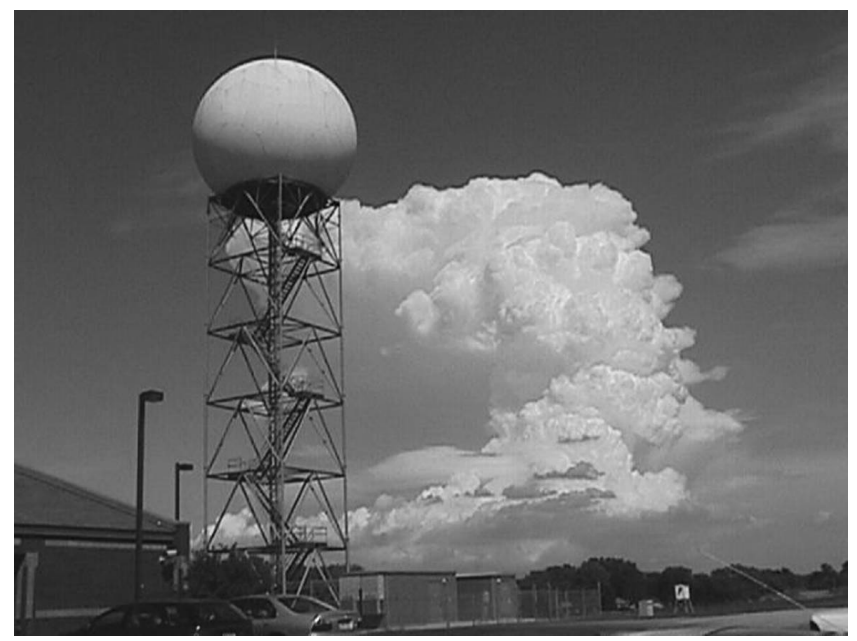

FIGURE 12.1 A WSR-88D radar. (Photo courtesy of NOAA, Washington, DC.)

The reflected power returned to the $\operatorname{radar}(Z)$ is then assigned a rainfall rate $(R)$ using a conversion known as a $\mathrm{Z} / \mathrm{R}$ relationship. As the value $\mathrm{Z}$ increases, the $\mathrm{R}$ estimate in inches per hour increases exponentially based on the $\mathrm{Z} / \mathrm{R}$ equation employed. Within this precipitation rate subalgorithm, more quality control is performed using a time continuity test, as well as corrections for hail and range degradation. Next, precipitation accumulations are determined through interpolation of scan-to-scan rain accumulation while simultaneously running clock-hour accumulations. Precipitation products are then generated and updated with each volume scan (NWS/ROC, 1999). An important end product is the hourly Digital Precipitation Array (DPA) product that provides $1 \mathrm{~h}$ estimates of rainfall on the $4 \mathrm{~km}$ HRAP grid discussed earlier. These DPAs are the one of four primary inputs to the MPE PPS program, a tool primarily used east of the Rocky Mountains, which will be discussed later in Section 12.4.

\subsubsection{Problems with Radar-Based Precipitation Estimates}

The WSR-88D precipitation algorithm is not without deficiencies and limitations, which all operational radars experience when attempting to estimate rainfall. Many factors that make accurate radar precipitation estimates difficult have been well documented (Wilson and Brandes, 1979; Hunter, 1996). The following text is a brief description of some of these factors and how they affect precipitation estimates.

\subsection{Radar Reflectivity Calibration}

Precipitation estimates can experience significant error if the reflectivity (i.e., value of returned power) from a rainfall target is too large or too small (Chrisman and Chrisman, 1999). The WSR-88D calibrates reflectivity before every volume scan using internally generated test signals. These calibration checks should maintain an accuracy of $1 \mathrm{dBZ}$, which translates to an accuracy of $17 \%$ in rainfall rates when the default $\mathrm{Z} / \mathrm{R}$ relationship $\left(\mathrm{Z}=300 \mathrm{R}^{1.4}\right)$ is employed. However, hardware problems 
(such as a change in actual transmitted power, or path loss of the returned power before reaching the receiver signal processor since the last off-line calibration) can cause significant changes in absolute calibration over time. Absolute calibration needs to be maintained because a change in $\mathrm{Z}$ of $\pm 4 \mathrm{dBZ}$ will result in doubling (or halving) the estimated $\mathrm{R}$ when the default $\mathrm{Z} / \mathrm{R}$ relationship is used. Therefore, the WSR-88D Radar Operations Center (ROC) has developed absolute calibration procedures that are designed to ensure that reflectivity data are accurate to within $\pm 1 \mathrm{dBZ}$.

\subsection{Proper Use of Adaptable Parameters}

As mentioned earlier, several adaptable parameters have a bearing on the precipitation algorithm, including parameters defining the Z/R relationship and the maximum precipitation rate (MXPRA). In the WSR-88D, the default Z/R relationship is the convective $\mathrm{Z}=300 \mathrm{R}^{1.4}$, and the default MXPRA is established at $53 \mathrm{dBZ}$, which equates to a maximum rainfall rate of $\sim 104 \mathrm{~mm} / \mathrm{h}(4 \mathrm{in} . / \mathrm{h})$ when the convective $Z / R$ is employed. This value of MXPRA was established to eliminate the effects of hail contamination on rainfall estimates, as water-coated ice in clouds returns larger reflectivity values than liquid water alone would produce. However, extreme rainfall rates above the default MXPRA have been shown to occur when a deep warm cloud layer exists and warm rain processes prevail, which is most prevalent in tropical rainfall regimes where larger water drop size diameters exist (Baeck and Smith, 1998) and hail is absent. To compensate for this, radar operators have the option of using a different $\mathrm{Z} / \mathrm{R}$ relationship called the Rosenfeld tropical $\mathrm{Z} / \mathrm{R}\left(\mathrm{Z}=250 \mathrm{R}^{1.2}\right)$. When the tropical $\mathrm{Z} / \mathrm{R}$ relationship is employed, significantly more rainfall is estimated for reflectivities higher than $35 \mathrm{dBZ}$ (Vieux and Bedient, 1998). For example, the convective $Z / R$ relationship yields a rainfall rate of $28 \mathrm{~mm} / \mathrm{h}$ (1.10 in./h) when $\mathrm{Z}=45 \mathrm{dBZ}$, while the tropical $\mathrm{Z} / \mathrm{R}$ yields double the rainfall rate of $56 \mathrm{~mm} / \mathrm{h}$ (2.22 in./h). Three additional Z/R relationships have been approved for use by the ROC: the Marshall-Palmer relationship $\left(Z=200 \mathrm{R}^{1.6}\right)$ for warm or arid climates where rainfall events are mostly stratiform in nature and two cool-season stratiform relationships (East $Z=200 R^{2.0}$ and West $Z=75 R^{2.0}$ ). Radar operators may also change the MXPRA parameter so that a higher rainfall rate will be used in the precipitation accumulation function to a maximum of $152 \mathrm{~mm} / \mathrm{h}(6.00 \mathrm{in} . / \mathrm{h})$. In general, changes in the Z/R relationship have been shown to be extremely important in radar precipitation estimation (Fournier, 1999), while changes in MXPRA have far less impact.

Two other important adaptable parameters (RAINA and RAINZ) control when rainfall accumulations start and stop (Boettcher, 2006). Rainfall underestimation can occur if these parameters are set such that accumulations begin too late and/or end too early. RAINA is the minimum areal coverage of significant rain with a default setting of $80 \mathrm{~km}^{2}$. RAINZ is the dBZ threshold that represents significant rain (i.e., the level of returned power for which you desire to begin radar rainfall accumulation) with a default setting of $20 \mathrm{dBZ}$. When the reflectivities of echoes are at or above RAINZ and the total areal coverage of returns meets or exceeds RAINA, the precipitation algorithm will accumulate rainfall. If these parameters are not adjusted for the rainfall type noted on any given day, this would have implications 
for drought monitoring. If a rain event is isolated (covering less than $80 \mathrm{~km}^{2}$ ) or if the $\mathrm{dBZ}$ detected is less than the minimum defined level, then rainfall will not be accumulated. This could introduce a "dry bias" such that, if it is consistent over a period of time, it would indicate a signal drier than the rainfall that is actually received.

\subsection{Hail Contamination, Bright Band, Snow, and Subcloud Evaporation}

The presence of frozen or wet frozen precipitation can cause significantly enhanced reflectivity values (Wilson and Brandes, 1979). As hail stones grow in size, they become coated with water and reflect high amounts of power back to the radar, which can be significantly higher than the power returned from liquid precipitation present within the storm. The hail-contaminated higher power value results in an overestimation of the precipitation reaching the ground. Similarly, when ice crystals fall through the freezing level, their outer surfaces begin to melt. These water-coated ice crystals also produce abnormally high reflectivities, which lead to "bright band" enhancement (the layer of the atmosphere where snow melts to rain) and an overestimation of the precipitation.

Snowflakes are sampled fairly well by radar, but improper Z/R relationships can lead to an underestimation of the snowfall by the WSR-88D. A snow accumulation algorithm (SAA) has been added using a more representative relationship between reflectivity and frozen precipitation (Z/S relationship, identical to the East or West cool season stratiform Z/R relationship) to improve the water equivalent snowfall estimates. Vasiloff (2001) and Barker et al. (2000) provide more detailed review of the SAA.

Subcloud evaporation below the radar beam will also cause overestimation. This occurs when the rain falls into a dry subcloud layer and is most likely to occur in locations where clouds frequently have very high bases. In this situation, the rainfall estimate in the cloud may be relatively accurate, but the estimate will be too high if little or no rainfall reaches the ground. A prime example of this is virga (or dry microbursts).

\subsection{Range Degradation}

At far ranges, rainfall rates may be reduced because of signal degradation from partial beam filling that occurs when the radar beam widens with distance from the antenna and precipitation fills only part of the beam's field of view. Although the capability exists for range correction, it is currently not implemented on the WSR-88D pending scientific data to support accurate parameterization. Two other range degradation problems are more significant compared to partial beam filling. Certain rainfall types, such as stratiform rains (e.g., rainfall from clouds of extensive horizontal development as opposed to vertically developed convective clouds), show strong vertical reflectivity gradients. The stratiform gradient is positive until you get past the "bright band," and then it decreases sharply, leading to an overestimation of precipitation close to the radar and an underestimation with greater range. Orographic rain events also have sharp vertical reflectivity gradients as can certain rainfall events associated with distinct meteorological lifting surfaces such as a warm front. A rainfall event with a sharp vertical reflectivity gradient will show fairly strong range degradation. The reflectivity values decrease 
so rapidly with height within a cloud that the radar will have a higher degree of underestimation as the radar beam increases in altitude. In such rainfall events, the beam height becomes the largest single contributor to radar rainfall underestimations. Last, in stratiform rain events and with rains from thunderstorms that have small vertical height (usually 20,000 ft or less), a rainfall underestimation occurs due to the radar beam overshooting the precipitation at far ranges, which is a lack of detection problem. To compensate for this, the NWS set up the NEXRAD radar network with a spatial distribution of roughly $300 \mathrm{~km}$ apart. Figure 12.2 shows the WSR-88D radar coverage area for the United States. Notice that many sections of the western United States are without adequate radar coverage, which leads to unrepresentative precipitation estimates. Thus, radar- and range-dependent low precipitation biases can accumulate over time, leading to an underestimation of precipitation and a depiction of drier conditions. Users should understand this issue before using these estimates to evaluate drought conditions and other informational products.

\subsection{Anomalous Propagation and Clutter Suppression}

The WSR-88D displays reflectivity returns at locations assuming the beam is refracting normally in a standard atmosphere. At times, severe deviations from the standard atmosphere occur in layers with large vertical gradients of temperature and/or water vapor. When these deviations occur, super-refraction of the radar beam can result, and inaccurate calculations of actual beam height are made. These changes in refraction usually occur in the lower troposphere and can lead to persistent and quasi-stationary returns of high reflectivity either from ducting of the radar beam (where radio waves traveling through the lower atmosphere are curved to a value greater than the curvature of the earth) or from the beam coming in contact with the ground (Chrisman et al., 1995). This AP can lead to extreme precipitation accumulation estimates from false echoes. The WSR-88D does employ a clutter mitigation decision algorithm, which allows the radar operator to filter undesirable reflectivity returns, often from permanent targets near the radar (Maddox, 2010). However, this capability depends on the radar operator's ability to recognize the AP and invoke the algorithm. Improper or excessive use of clutter filtering may cause real meteorological echoes to be unnecessarily removed, leading to rainfall underestimation. This occurs most frequently when real rainfall targets are embedded in or near areas of AP, which is common behind a line of strong thunderstorms. Also, precipitation estimates from nonmeteorological targets (such as wind farms) are still observed on precipitation products, as certain targets that exhibit motion are not removed using current clutter filtering techniques. Figure 12.3 shows an example of AP across the south-central United States caused by superrefraction of the beams of several radars. Note the widespread light rainfall indicated over Oklahoma and central and deep south Texas and heavy rain over the Gulf of Mexico. No rainfall was actually occurring at this time. For hydrologic applications, this false rainfall is eliminated by conducting further data quality control external to the WSR-88D and is performed within the MPE PPS at RFCs. 


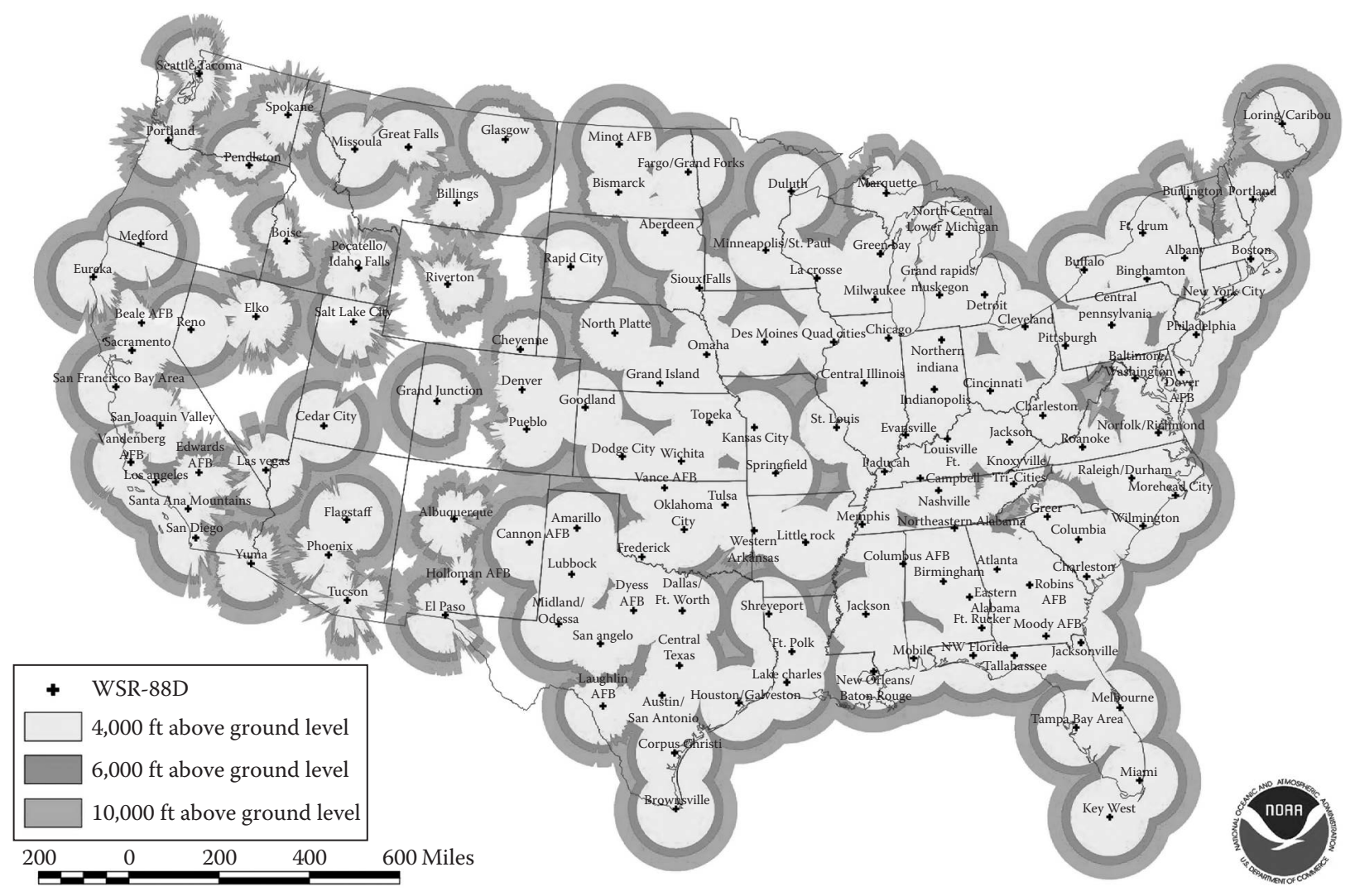




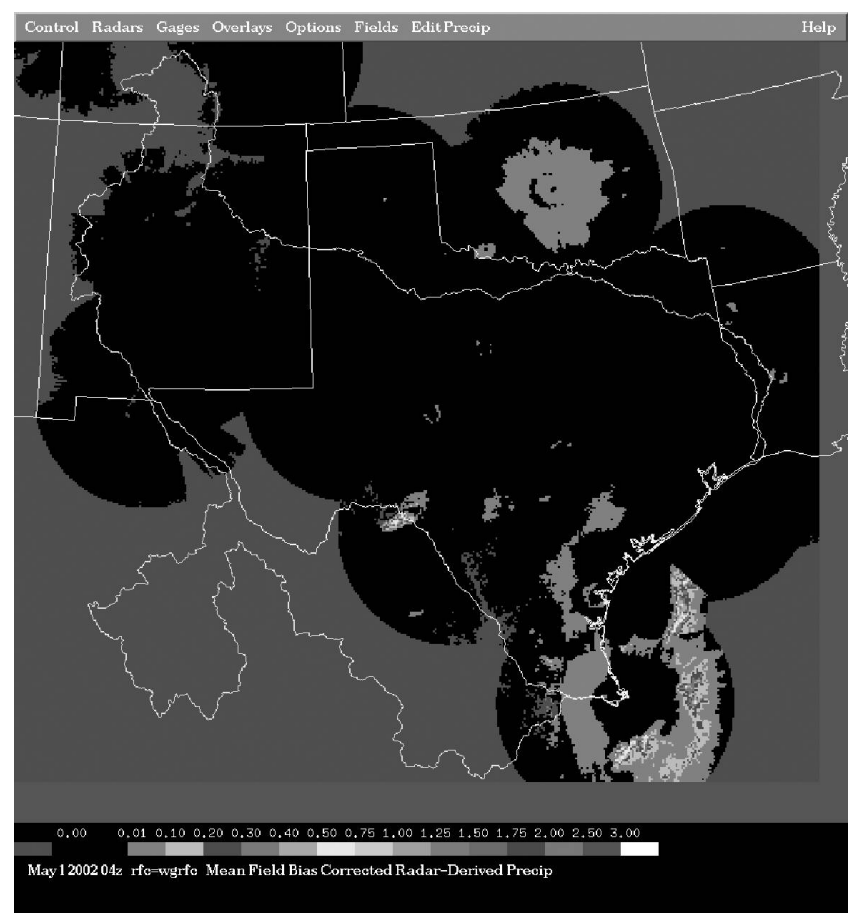

FIGURE 12.3 (See color insert.) Widespread false precipitation, or AP, shown on the MPE radar mosaic. (Photos courtesy NOAA/NWS, Silver Spring, MD.)

\subsection{Beam Blockage}

Beam blockage is a major problem where radars are situated near mountains and is unavoidable in many western U.S. locations. For radials (portions of the circular scan of the radar at a set elevation angle) with a blockage of no more than $60 \%$ in the vertical and $2^{\circ}$ or less in azimuth, corrections are made to the reflectivities and are increased by $1-4 \mathrm{dBZ}$ in the range bins beyond the obstacle, depending on the percentage of the blockage. Many sites have beam blockages of more than $60 \%$ and greater than $2^{\circ}$ in azimuth, and this correction cannot be applied. Instead, the WSR88D employs a terrain-based hybrid scan (O'Bannon, 1997), so radials that experience this high degree of beam blockage use the next higher elevation slice (complete scan of the radar at a set elevation angle) for the PPS for that radial (up to a maximum elevation angle of $3.4^{\circ}$, which is the fourth elevation slice aboveground). However, if a higher elevation slice is employed, range degradation is more likely, leading to underestimation of the precipitation. As a result, precipitation underestimation is common from radars located near mountains. The problem has been mitigated at some sites by installing radars on a peak. However, in this situation, the lowest elevation slices are so high above valleys that near-surface precipitation is not detected, which leads to the underestimation of rainfall from clouds of low vertical extent. Figure 12.2 also illustrates the gaps in radar coverage over the western United States due to the mountainous terrain. 


\subsection{Attenuation}

The radar corrects for gaseous attenuation of the microwave radar signal, leaving a wet radar dome covering the antenna and intervening precipitation as the principal attenuators of energy to and from the target. Although this attenuation for S-band radars (10 cm wavelength) is considered to have minimal impacts on rainfall estimation, Ryzhkov and Zrnic (1995) show results indicating that attenuation may have a greater impact on rainfall estimates than previously thought. Signal attenuation could be one reason why rainfall is often underestimated during extremely heavy rain events due to reduced reflectivity returns, but it is difficult to quantify exactly how much the rainfall rates are reduced.

\subsection{Polarization}

The current WSR-88D is a single horizontal linear polarized radar. Dual polarization radar measurements of a specific differential phase at two orthogonal polarizations (horizontal and vertical) have shown improved skill in rainfall estimation compared to single polarization radars using Z/R relationships (Zrnic and Ryzhkov, 1999). Additional hydrometeor microphysical information can be inferred from the addition of vertical polarization measurements to obtain differential reflectivity, which aids in determining the size and type of liquid or frozen water particles (e.g., precipitation such as rain, sleet, hail, or snow), which would lead to improved precipitation estimation. A retrofit for the WSR-88D to implement dual polarization on a national scale is slated for 2011-2013. It has been determined that adding dual polarization capability to the WSR-88D will provide improved rainfall estimation for floods and drought and additional benefits that include improved hail detection for discriminating between liquid and frozen hydrometeors, rain/snow discrimination for winter weather, data retrieval from areas of partial beam blockage to improve services in mountainous terrain, and removal of nonweather artifacts such as birds and ground clutter to improve overall data quality for the precipitation algorithm.

\subsubsection{Benefits of Radar-Based Precipitation Estimates}

In spite of the limitations and some of the issues related to radar-based precipitation estimates, there are valid reasons for using them. A recent study by Krajewski et al. (2010) summarized the operational capability of radar to provide quantitative rainfall estimates with potential applications not only in hydrology but also in drought monitoring by improving gridded standard precipitation indices. Radar has the ability to show the spatial and temporal distribution of rainfall more accurately than other traditional sensors such as rain gauges. The timing and intensity of the rainfall is more easily determined because of the availability of hourly and subhourly estimates. Radar also provides a more accurate determination of rainfall location, which is critical for providing more local-scale information to the drought community about spatial variations in rainfall patterns and the identification of more localized areas experiencing precipitation deficits. This is far superior to waiting for $24 \mathrm{~h}$ rain gauge data to be reported and performing only a single calculation of MAP over a predefined geographic area (e.g., a river basin), as was the standard operating procedure in the past. 


\subsubsection{Rain Gauge Networks}

Rain gauge networks form a supplemental source of precipitation data concurrent to gridded precipitation estimates. Two basic types of rain gauge networks support NWS hydrologic operations. One network has the ability to transmit rainfall data in near real time, while the other stations report $24 \mathrm{~h}$ data once a day. These two types of networks will be discussed separately as follows.

\subsubsection{Near-Real-Time Gauges}

Several near-real-time rain gauge networks with the ability to report precipitation hourly or even at $15 \mathrm{~min}$ intervals exist. These include the Automated Surface Observing System (ASOS) rain gauges at airports, data collection platforms operated by the U.S. Geological Survey, and mesonet alert systems maintained by various cities, states, and river authorities. Although these gauges are part of different networks, they all use tipping bucket gauges (Figure 12.4a) to automate the quantification of precipitation amounts.

Unfortunately, although these data are important, they are not without error, which can be introduced by wind, tipping bucket losses, poor siting (e.g., blockage from buildings, trees, and other tall vegetation), frozen precipitation, electronic signal malfunctions, mechanical problems, and timing/coding issues related to the transmission of rainfall data. Linsley et al. (1982) showed that strong winds will cause all rain gauges, regardless of type, to undercatch the precipitation. For example, approximately a $10 \%$ loss is estimated at a $10 \mathrm{mph}$ wind speed, with losses often exceeding $50 \%$ at wind speeds over $39 \mathrm{mph}$. To help compensate for losses, ASOS tipping bucket gauges have a shield around them to disrupt the air flow over the top of the gauge (see Figure 12.4b). Tipping bucket gauges also tend to underreport intense rainfall when the rainfall rate exceeds the bucket's rate to discard the captured rain $(\sim 1.5 \mathrm{~s})$. Thus, they cannot be calibrated for 0.01 of an inch precision or well calibrated for high rainfall rates. Maintenance is also an issue because many gauges are located in remote locations and frequent site visits by technicians may not be possible. In general, automated gauges provide good quality rainfall data if the gauges have good exposure, are well maintained, are recording when the air temperature is above freezing, when wind conditions are relatively light $(15 \mathrm{mph}$ or less), and the rainfall rate is not in excess of $4 \mathrm{in} / \mathrm{h}$.

\subsubsection{Daily Reporting Gauges}

Gauge networks that report daily, $24 \mathrm{~h}$ rainfall totals are usually submitted by human observers who typically use a nontipping bucket type of gauge. Data received from these networks are considered to be of higher quality than the data received from the hourly automated networks partially because of the standard 4 in rain gauge or a weighing gauge used by the observers, which are typically free from some of the errors commonly encountered with tipping bucket gauges. The two best known daily gauge networks are the NWS Cooperative Observer (COOP) network and the Community Collaborative Rain, Hail and Snow (CoCoRaHS) network. We will discuss how these data are used to improve precipitation estimates produced by the RFC later in Section 12.4.5. 


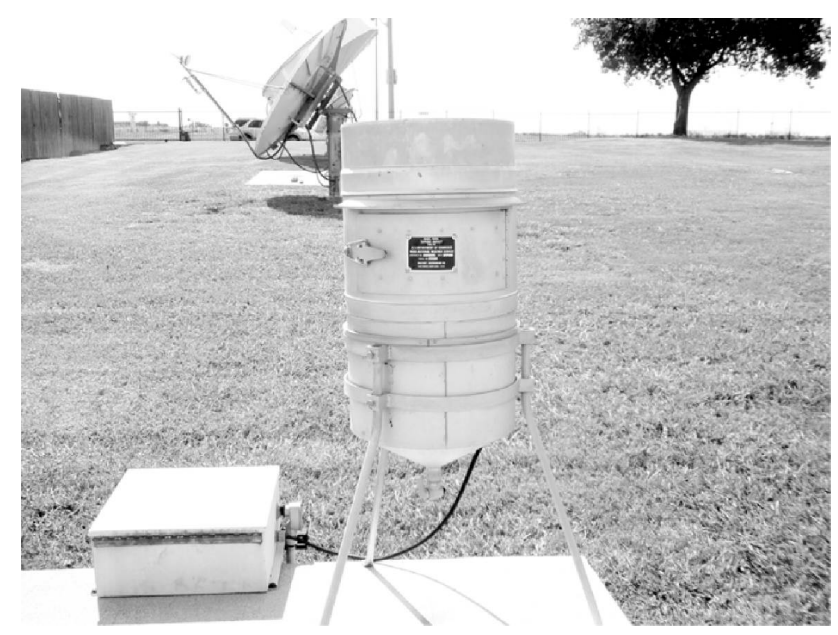

(a)

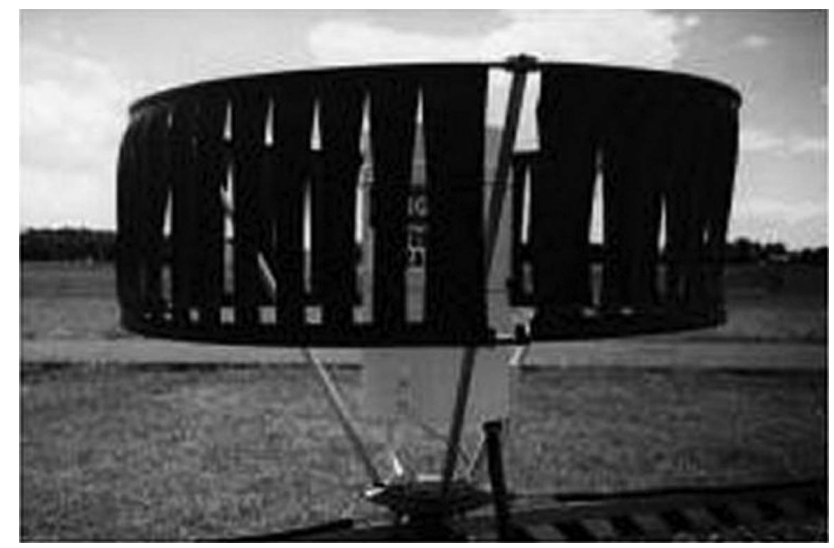

(b)

FIGURE 12.4 Tipping bucket rain gauge (a) and ASOS tipping bucket rain gauge with wind shield (b). (Photos courtesy of NOAA/NWS, Silver Spring, MD.)

\subsection{RADAR-BASED MULTISENSOR PRECIPITATION ESTIMATOR PRECIPITATION PROCESSING SYSTEM}

The main purpose of the MPE PPS is to take the raw hourly DPAs from the WSR-88Ds and perform additional quality control to achieve the best radar-based precipitation estimates possible for inclusion into the NWS River Forecast System (NWSRFS) for the primary purpose of river streamflow prediction. These estimates also hold considerable potential for providing both spatially and temporally explicit information about precipitation patterns and deficits over an extended period of time, which would greatly enhance the drought community's monitoring capabilities beyond the spatially interpolated precipitation grids generated from station observations that are currently used in operational monitoring systems. The following sections are a brief overview of the three PPS stages. 


\subsubsection{Three Stages of MPe Precipitation Processing}

\subsubsection{Stage I of the MPE PPS}

The first PPS stage ingests the hourly $4 \mathrm{~km}$ DPA data that are generated by the WSR$88 \mathrm{D}$, selecting the DPA that is timed closest to the top of each hour. The only quality control applied to the DPA data is features associated with the WSR-88D precipitation algorithm itself. Some of these features were discussed in Section 12.3.1, but for a more detailed discussion, see Story (1996).

\subsubsection{Stage II of the MPE PPS}

The second PPS stage calculates and applies a bias adjustment factor based on a comparison of rain gauge readings and radar precipitation estimates (Seo et al., 1999). Two biasing techniques are derived in the PPS: a mean-field bias and a local bias. The mean-field bias represents the ratio of the sum of all positive (nonzero) rain gauge data over the radar umbrella from the previous $x$ number of hours to the sum of all nonzero DPA rainfall estimates at the corresponding gauge locations over the same temporal sampling window. The size of the temporal window $x$ is specified by the adaptable parameter "mem-span" (memory span in hours, determined as a function of how widespread the rainfall is, how many gauges are available for sampling, and how long ago since it last rained). The MPE program calculates a mean-field bias for 10 memory spans, ranging from the current hour (instantaneous bias) to 10,000,000 h (climatological bias). The program also has an adaptable parameter that tells MPE which bias calculated from the 10 memory spans to apply to the DPA file. The default for this adaptable parameter is a minimum of 10 radar-rain pairs (called N-Pairs) for a mean-field bias to be applied to the "raw" radar rainfall estimate. If there are 10 or more N-Pairs for mem-span 1, the program uses the bias calculated from the radargauge pairs from the current hour. If there are no $10 \mathrm{~N}$-Pairs for the current hour, the program goes back in time until a mem-span is found where 10 radar-gauge pairs are achieved. A time-weighting factor is applied to older N-Pairs so that the most recent data carry the most weight in these calculations. For example, if the bias calculated from mem-span 720 is used, the program had to go back between 168 (the maximum number of hours from the previous mem-span) and $720 \mathrm{~h}$ to find enough rain events that had at least $10 \mathrm{~N}$-Pairs, which would include all nonzero radar-gauge pairs from the past 30 days. In general, the denser the rain gauge network is, the shorter the mem-span, unless a drought is in progress or the radar samples an area in a dry climate. In times of drought, the mem-span continues to increase over time as few $\mathrm{N}$-Pairs are achieved, leading to the possibility that when it does rain again, the bias calculation will be inappropriate. The goal of MPE is to capture the temporal variability of the bias for different rainfall regimes to allow for the variability of radar precipitation estimates. A detailed description of all MPE functionality can be found in the MPE Editor User's Guide (NWS/OHD/HL, 2010).

In short, the larger the number of rain gauges located under a radar umbrella, the better chance the program has of obtaining nonzero radar/rain gauge pairs and calculating a mean-field bias. Under radar umbrellas that have a large number of 
hourly rain gauges available, the calculated MPE mean-field bias adjustment factor is a good indicator of whether a radar is over- or underestimating rainfall. A bias of 1.00 means that the MPE program has accepted the radar estimates as correct. If the mean-field bias adjustment is greater than 1.00, the radar is underestimating compared to its associated gauges, and if a bias is less than 1.00 , the radar is overestimating rainfall. This factor is used to either increase or decrease the precipitation estimates in the MPE mean-field bias adjusted analysis.

In addition to the mean-field bias (one bias for each radar), a local bias technique is also calculated in the MPE program, assigning a bias correction factor for each HRAP grid box (or cell) in the MPE area. Like the mean-field bias, local bias values are computed by comparing gauge values to raw radar estimates. They are also processed over 10 memory spans, selecting the memory span whose bias value has at least 10 contributing gauge/radar pairs falling within a $40 \mathrm{~km}$ radius circle around each HRAP grid box for which a bias factor is being computed. The resulting grid of local bias values is then applied to the raw radar mosaic (similar to how the mean-field bias is applied) to produce the local bias-corrected radar mosaic. By computing the bias for each HRAP grid box, local geographical and microclimatological effects on rainfall can be accounted for (Seo and Breidenbach, 2002). Because of this accounting, the chosen default MPE field at many RFCs is the local bias multisensor field (i.e., the combination of the local bias radar mosaic and a gauge-only analysis).

In addition to the biased radar mosaics, a gauge-only gridded field is derived using hourly rain gauge observations, which must be quality controlled at this stage (Fulton et al., 1998). Tools exist within MPE (such as a gauge table) that allow HAS forecasters to detect rain gauge readings that subjectively appear to be inaccurate. Although rain gauge data are often referred to as "ground truth," these data also have known deficiencies, as mentioned in the previous section. However, the West Gulf RFC (WGRFC) HAS forecasters have found that most rain gauge data received are of acceptable quality and can be used (with some caution) to make accurate bias adjustments during most events. If any gauge reading appears incorrect (e.g., when radar fields are nonzero and a gauge reads zero), it is removed by the HAS forecaster, and all the MPE fields are regenerated. This may cause a change in the bias adjustment factors for one or more radars and in the gauge-only fields. The end result of this second stage is an adjusted radar precipitation estimate for each WSR-88D defined in the MPE program.

\subsubsection{Stage III of the MPE PPS}

In stage three of the PPS, the adjusted radar fields (those derived in Stage II, which were discussed in the previous section) are merged with the derived gauge-only field to calculate the final multisensor fields. The multisensor field of the specific radar site is then mosaicked with the multisensor fields of other radar sites to obtain the final multiradar precipitation map. Two primary multisensor fields are created in MPE, one for each biasing technique described in the previous section. The HAS forecaster makes a determination of which multisensor field is estimating correctly each hour (to use as our best estimate field, discussed further in the next two sections). 
These multisensor fields are created for the areal extent covered by each RFC and are used daily by the National Centers for Environmental Prediction (NCEP) to generate a national Stage IV quantitative precipitation estimation (QPE) product. The HAS forecaster has other quality control options within the MPE program, such as the removal of AP. For a more detailed discussion of precipitation processing, see Story (2000).

\subsubsection{Q2, the Next-Generation QPE}

The WGRFC has been experimenting with a new precipitation estimation technique called Q2, which is the second technique derived by research meteorologists at the National Severe Storms Laboratory (NSSL). The National Mosaic and Multisensor QPE (NMQ) project is a joint initiative between the NSSL and other entities (such as the Federal Aviation Administration [FAA] and the University of Oklahoma). The National Mosaic and Q2 system is an experimental system designed to improve QPE and eventually very short-term Quantitative Precipitation Forecasts (QPF). For detailed information on the system, readers are referred to the NMQ web site at http://nmq.ou.edu. The NMQ ingests data from $128 \mathrm{WSR}-88 \mathrm{D}$ stations every $5 \mathrm{~min}$, quality controls the radar data, and derives a vertical profile of reflectivity from each radar. Analyses are done on eight tiles of radar data that are stitched together to form a continental U.S. (CONUS) three-dimensional (3-D) grid. Hybrid scan reflectivity and other products (such as a composite reflectivity map and precipitation flag product) are then derived to produce the experimental Q2 products. The products (such as QPE accumulations for the current hour or several hours of up to $72 \mathrm{~h}$ ) are then translated over to the $4 \mathrm{~km}$ HRAP grid. The Q2 products hold several advantages over traditional radar-based estimates, with two primary advantages including an AP removal technique and rainfall estimates beyond the nominal $230 \mathrm{~km}$ range of the DPA files that are used in regions where radar umbrellas do not overlap. Because of these advantages, WGRFC HAS forecasters have the option of implementing Q2 as our final best estimate field.

\subsubsection{Satellite Precipitation Estimates}

The MPE also ingests satellite-derived precipitation estimates from the National Environmental Satellite, Data, and Information Service (NESDIS). The Hydroestimator is an automated technique, initially designed for large, moist thunderstorm systems, which uses Geostationary Operational Environmental Satellite (GOES) infrared (IR) imagery cloud top brightness temperatures (Scofield and Kuligowski, 2003). Pixels with the coldest IR temperatures are assigned the heaviest rainfall rates at the surface. Numerous other factors, including the cloud-top geometry, the available atmospheric moisture (precipitation efficiency), stability parameters from weather models, radar, and local topography, are used to further adjust the rain rates. Although caution should be used in drawing conclusions about radar performance based on satellite-derived precipitation estimates, HAS forecasters can confirm radar performance if the precipitation estimates from both sources are in close agreement. However, correlation coefficients comparing $24 \mathrm{~h}$ satellite 
precipitation estimates (SPEs) to $24 \mathrm{~h}$ rain gauges show the lowest correlation of any of the remote-sensing fields (biased radar estimates or Q2) used by HAS forecasters. Therefore, satellite-based estimates have the most benefit over land areas where no or limited observations of precipitation (e.g., radar, Q2, or rain gauges) are available (e.g., border area of Mexico). SPEs can be used without bias correction, or can be corrected for local biases using the techniques described earlier for radar. And like the other fields previously discussed, the option exists to integrate SPEs into our final best estimate precipitation field by performing polygon edits. One example of when SPEs would be integrated is when lightning data indicate thunderstorm activity and SPEs are the only field estimating rainfall in this location. As a result, the final best estimate field is based on a combination of radar-based multisensor fields from DPA files, Q2, and SPEs.

\subsubsection{Final Postanalysis Quality Control Technique}

Hundreds of $24 \mathrm{~h}$ COOP rainfall reports and CoCoRaHS observations are available for postanalysis of the MPE results. Direct comparisons of the MPE and observer rainfall totals shortly after 12 Coordinated Universal Time (UTC) each morning allow HAS forecasters to determine areas where the MPE estimates may be too low or too high. Forecasters can raise or lower estimates in specific hours in order to produce a $24 \mathrm{~h}$ estimate that is more consistent with $24 \mathrm{~h}$ gauge reports. The goal is to achieve a "general" level of acceptable error in the estimates. Programs are run that show the correlation coefficient and percent bias of MPE estimates, which vary by time and location. The goal is to modify the estimates to achieve correlation coefficients of greater than 0.85 . Most initial estimates are low (meaning the $24 \mathrm{~h}$ gauge reports are higher than MPE) and have correlation coefficients of less than 0.85. When initial MPE estimates are raised or lowered, the inherent error of most estimates is improved to the desired correlation. Since these data are to be used for improved drought monitoring, removal of the traditional underestimation is crucial. If these biases are not mitigated, a false identification of the onset of drought might occur over time.

\subsection{DROUGHT MONITORING: HOW THESE ESTIMATES CAN BE USED TO DETERMINE CURRENT LOCATIONS OF DROUGHT}

\subsubsection{NWS Southern Region Precipitation Analysis Project}

In the early and mid-2000s, NWS Southern Region offices began to display the gridded MPE output maps on the Internet, and the data became available for download a short time later. Initially, these pages graphically showed the short-term observed and climatic trends of precipitation across the southern region (from New Mexico eastward to Tennessee, Georgia, and Florida). In 2009, this project was expanded to include the entire CONUS and Puerto Rico. The national-level products can be found on the Advanced Hydrologic Prediction Service (AHPS) web site (http://water.weather.gov). Tools are also 
available to compare MPE estimates to normal rainfall over different timescales (http://water.weather.gov/precip/), which can provide valuable insight into detailed spatiotemporal patterns of precipitation deficits to characterize both short- and long-term drought conditions.

"Departure from Normal" and "Percentage of Normal" products are generated by using simple grid mathematics, where the "Normal" data set is respectively subtracted from or divided into the "Observed" data set. "Observed" data are derived from output (e.g., from MPE or similar PPSs) from 12 NWS RFCs. "Normal” precipitation is derived from Parameter-elevation Regressions on Independent Slopes Model (PRISM) climate data (Gibson et al., 2002), which represent a 30 year period of record (1971-2000). The data sets were created as a unique knowledge-based system that uses point measurements of precipitation, temperature, and other climatic factors to produce continuous, digital grid estimates of monthly, yearly, and event-based climatic parameters. This unique analytical tool incorporates point data, a digital elevation model, and expert knowledge of complex climatic extremes, including rain shadows, coastal effects, and temperature inversions. In order to fill in areas that have radar-coverage gaps in the mountainous western United States, gauge reports are plotted against long-term climatic PRISM precipitation data, and amounts between gauge locations are spatially interpolated (more information about this method is available at http://www.cnrfc.noaa.gov/products/rfcprismuse.pdf). The derived precipitation products (specifically, "Departure from Normal" and "Percentage of Normal" products) can provide useful contextual information to identify the amount and magnitude of precipitation deficits that can be used for drought monitoring.

Figure 12.5 shows an example of a percent of normal rainfall graphic from December 2010 across the southern United States. This month was exceptionally dry, and this graphic depicts few areas where percent of normal precipitation

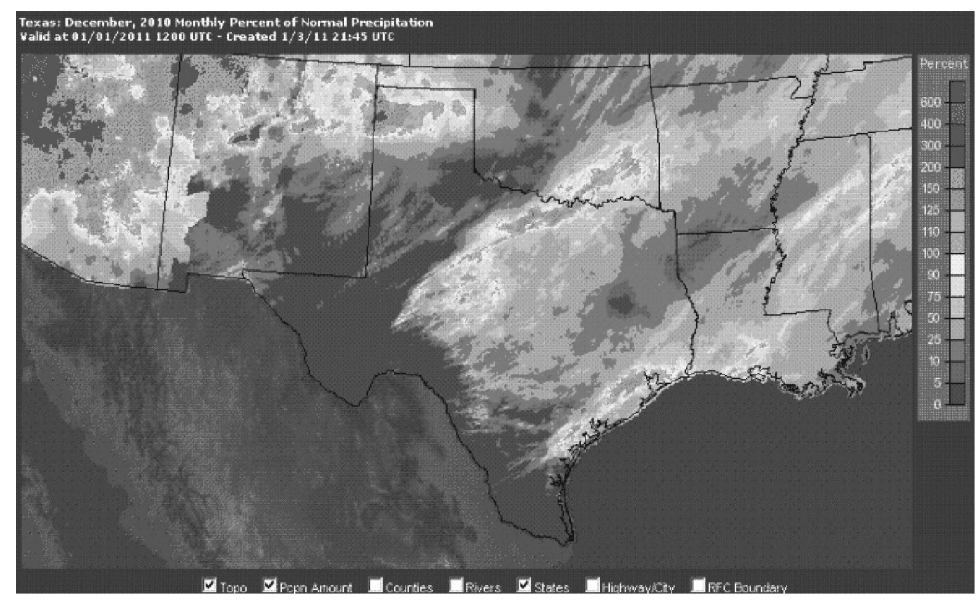

FIGURE 12.5 (See color insert.) Percent of normal rainfall for the southern United States from the AHPS precipitation analysis page for December 2010. (Image courtesy of NOAA/ NWS, Silver Spring, MD.) 
exceeded $100 \%$ (the upper Texas Gulf coast near Houston was one area). Of note are the large regions where the percent of normal precipitation was less than $50 \%$ of normal, specifically from northern Louisiana into east-central Texas, and across the Texas/Mexican border to western Texas. This indicates a strong dry signal, collocated with an extreme drought category designated on the USDM (not shown) for these locations.

\subsubsection{Advanced Hydrologic Prediction Service}

Before 2009, all radar-based product data displayed by the Southern Region Precipitation Analysis Project were considered to be "experimental." To make these data "operational," the data pages were packaged into a nationwide program known as the AHPS, a new and essential component of the NWS Climate, Water, and Weather Services. AHPS is a web-based suite of products that display drought magnitude and uncertainty of occurrence, based on the range of potential outcomes computed from historical hydrometeorological data and current conditions using an ensemble streamflow prediction model. These new products are enabling the USDM, National Drought Mitigation Center (NDMC), government agencies, private institutions, and individuals to make more informed decisions about risk-based policies and actions to mitigate the dangers posed by droughts. Although these products were not designed specifically for drought monitoring, the high-spatial-resolution precipitation information they provide has substantial potential to support this application. For example, the office of the Texas State Climatologist creates a gridded $4 \mathrm{~km}$ resolution and a county-scale resolution SPI from the AHPS precipitation analyses data (http://atmo.tamu.edu/osc/drought/). A more detailed description of the SPI grid generation using the AHPS is provided by Nielsen-Gammon and McRoberts (2009).

Traditionally, coarse resolution SPI maps derived from spatial interpolations of point-based gauge data have been used for drought monitoring, as shown in Figure 12.6a. In Figure 12.6b, the $4 \mathrm{~km}$ SPI maps generated from radar-based precipitation data depict considerably more spatially detailed precipitation variations, which provide considerably more local-scale information about precipitation deficits that is more appropriate for county to subcounty decision making related to drought. In brief, the SPI map generated from AHPS precipitation analyses is created using the following process. Initially, a cluster analysis is performed to determine Texas precipitation normals by location and season. A frequency distribution is then calculated for each location and season, from which high-resolution gridded frequency distributions are produced (using PRISM data over higher terrain of west Texas and roughly 1500 COOP stations in Texas and surrounding states). Finally, accumulations of precipitation are computed, creating $4 \mathrm{~km}$ and county-aggregated SPI for various time periods from 2 to 24 months, and related products such as an SPI blend, an SPI blend 1 week change map, and a percent of normal precipitation map.

The primary motivation for using AHPS precipitation data in this project was to facilitate local-scale drought monitoring for Texas. Climate division-scale drought monitoring tools are wholly inadequate for the state, and even ACIS gauge data are too coarse and unrepresentative in many areas. For example, the USDA applies the 


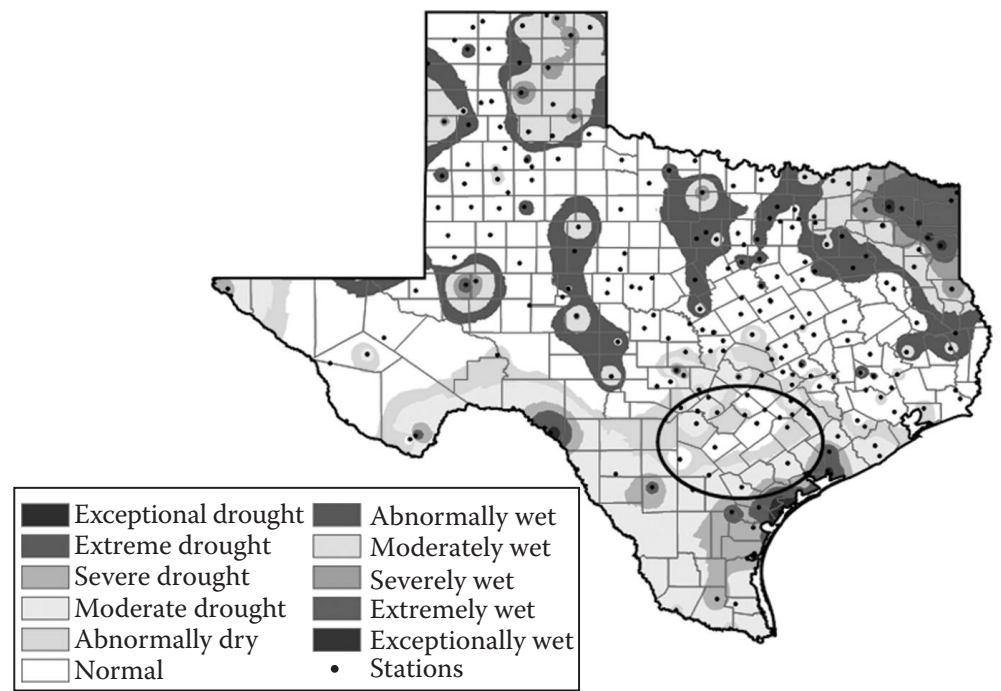

(a)

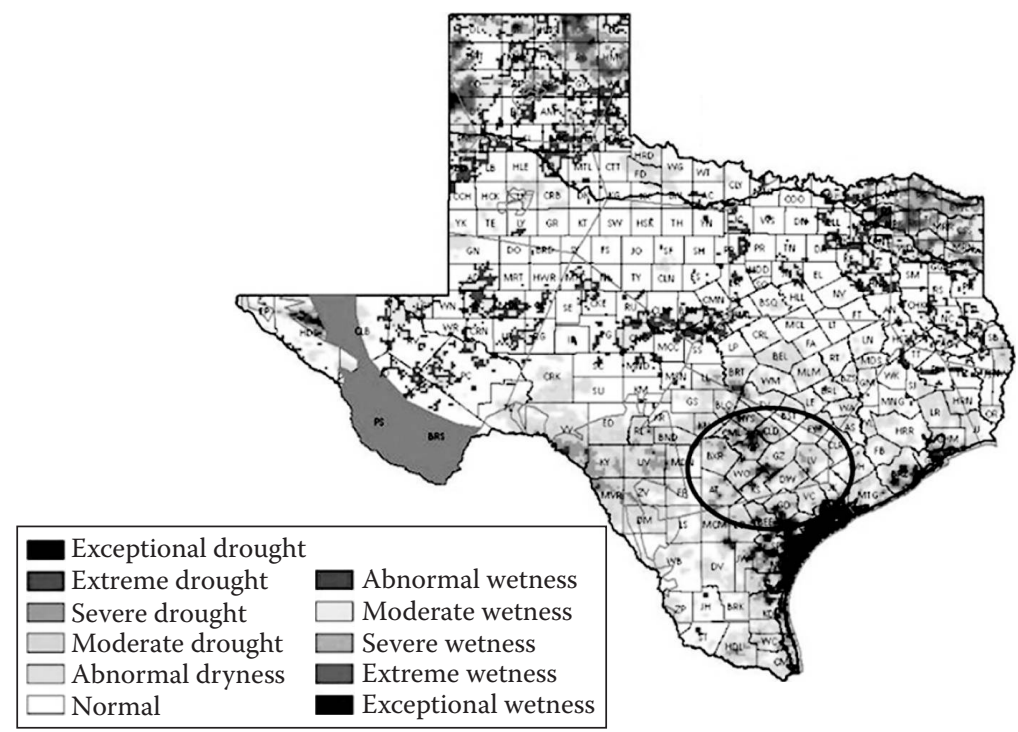

(b)

FIGURE 12.6 (See color insert.) An 8 week SPI map interpolated from station-based precipitation data (a) and an 8 week SPI map derived from $4 \mathrm{~km}$ precipitation from MPE (b) (Image courtesy of Dr. John Nielsen-Gammon) for early September 2009 during the severe drought in southern Texas, as shown by the USDM map on September 7, 2009 (c). The circle highlights an area of exceptional drought in the USDM that is shown to have nearnormal conditions in the interpolated SPI map (a) but clearly had localized areas of severe drought conditions that were detected in the SPI map based on higher-resolution, radar-based precipitation observations (b). 


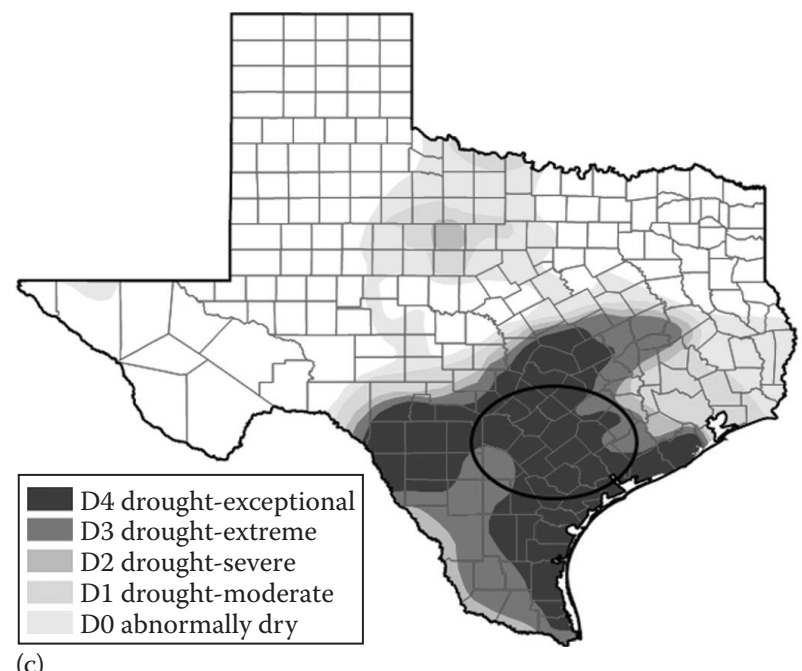

\section{FIGURE 12.6 (continued) (See color insert.)}

USDM map on a county scale for its drought relief decisions, yet the USDM and other existing drought index tools do not have the sufficient spatial resolution to enable estimation of drought at this spatial scale within Texas. An example of the SPI blend for Texas during the 2009 drought can be seen in Figure 12.6b. During this drought, the MPE-based SPI blend was able to accurately highlight the locations of most severe drought in Texas. Gauges within these hardest-hit areas, as indicated by our MPE products, were indeed experiencing historic drought severity based on an analysis of the period-of-record data, while stations adjacent to these areas were not. Nine counties (Nueces, San Patricio, Aransas, Refugio, Jackson, Calhoun, Bee, Brazoria, and Goliad) experiencing unprecedented drought severity were identified in southern Texas along the Gulf coast using MPE data, even though most of those counties did not have long-term precipitation records because of the sparse number of COOP stations that had a long history in that region (Nielsen-Gammon, August 2010, personal communication). Without the long-term precipitation records, SPI blends based on MPE data provided information that improved the assessment of the severity of the local drought situation.

In contrast, Figure 12.6a shows a station-based SPI map with data taken from the NDMC's Drought Atlas for the same time period as Figure 12.6b. Eight-week SPI data from 475 weather stations (226 stations in Texas and 249 stations from the surrounding states to minimize edge effects during the spatial interpolation of the SPI point data) were used to generate the map in Figure 12.6a. The stationbased SPI shows the overall location of exceptionally wet conditions (northeast Texas and the eastern Texas panhandle) and exceptional drought (middle Texas Gulf Coastal region). But it is clear that the station-based SPI missed how widespread the extreme and exceptional drought conditions were across south-central Texas. For example, in several counties in south-central Texas where the stationbased SPI showed normal conditions to abnormally dry conditions (Comal County 
eastward to Gonzales County), the MPE-based blended SPI showed severe to extreme drought conditions. Since hourly gauge data are incorporated into the final multisensor MPE, the drought features that appear over this area in Figure $12.6 \mathrm{~b}$ should be representative of relative precipitation patterns (and deficits) at a local subcounty scale because ground-based precipitation observations are considered in the adjusted, radar-based precipitation fields. Across this area of Texas, notable rainfall discrepancies among stations during the defined SPI interval were likely due to the convective nature of the rainfall in this region, with the interstation variations being relatively consistent with the drought/nondrought patterns depicted in Figure 12.6b. The USDM map for September 8, 2009 (Figure 12.6c), reaffirms the severe drought conditions over this area, classifying these counties in the most severe drought class (D4, an exceptional drought that is defined as a one in 50 year event). Further visual analysis of the MPE-derived SPI map of the area reveals many subtle subcounty variations in dryness that are not detected in the station-based SPI map. Many counties in southern Texas have pockets of both drought and nondrought conditions in the radar-generated SPI map that cannot be spatially resolved using traditional interpolated maps from station-based observations.

The use of $4 \mathrm{~km}$ precipitation data provides a more accurate depiction of the breadth and scope of the Texas drought conditions in 2009. This result suggests that the improved spatial resolution of this information will be a tremendous benefit for local-scale drought monitoring activities by characterizing detailed subcounty spatial variations in precipitation deficits. The $4 \mathrm{~km}$ precipitation and other derivative products such as the SPI will also be extremely valuable in areas with sparse weather station networks and for counties with large areas that commonly experience considerable within-county climate variations.

\subsection{CONCLUSIONS}

Over the past several years, advancements have been made in both radar-based precipitation sensing and multisensor estimation processing techniques. Further improvements will be made in radar precipitation estimation with the implementation of dual polarization in the next few years. New rainfall rate algorithms such as Q2 have also been implemented within the MPE PPS. This chapter has discussed the benefit that improved, quality-controlled, and finer-scale precipitation data can have in drought monitoring by detailing deficits in rainfall with greater spatial resolution that is not available using gauge-based SPI data alone.

East of the Continental Divide, RFCs derive estimates of precipitation using a multisensor approach. Hourly precipitation estimates from WSR-88D radars are compared to ground rainfall gauge reports, and a bias (correction factor) is calculated and applied to the radar field. The radar and gauge fields are combined into a "multisensor field," which is quality controlled on an hourly basis. In areas with limited or no radar coverage, SPE can be incorporated into this multisensor field, and the SPE can also be biased against rain gauge reports. In mountainous areas west of the Continental Divide, a different method is used to derive the 
estimates of precipitation. Gauge reports are plotted against long-term climatological precipitation (PRISM data), and derived amounts are interpolated between gauge locations.

Studies have shown (Seo, 1999; Seo and Breidenbach, 2002) that algorithms that combine sensor inputs_radar, gauge, and satellite-yield more accurate precipitation estimates than those that rely on a single sensor (i.e., radar only, gauge only, and satellite only). Although it is not perfect, the MPE data set is one of the best sources of timely, high-resolution precipitation information available. Still, users should understand the inherent weaknesses of this data set before using it in drought monitoring applications, especially those that require a high degree of accuracy.

Many quantitative measures of drought have been developed in the United States, depending on the sector impacted, the region being considered, and the particular application. Although different definitions and measures of drought exist, they all originate from a deficiency of precipitation resulting from an unusual weather pattern. Therefore, using an improved source of precipitation data such as MPE $4 \mathrm{~km}$ products would lead to a better determination of the onset, intensity, and geographic and temporal evolution of drought.

Several of the Palmer indices and the SPI are useful for describing drought on varying temporal scales (i.e., weeks, months, or years). On a climate-division scale, a standard suite of products including the NCDC's SPI, the CPC's soil moisture-related drought severity index, and the Western Region Climate Center's SPI exist. On a station scale, the U.S. Geological Survey provides gauge-based streamflow data, and the High Plains Regional Climate Center produces a 30 day SPI using daily data from ACIS that incorporates COOP observer and automated weather data. Satellitebased tools such as VegDRI (Brown et al., 2008) that assist in agricultural-related drought monitoring also rely on precipitation data as a primary input. Collectively, these drought indices have relied on gauge-based data and have not provided indices representative of county- to subcounty-scale drought information because of the coarse spatial resolution inputs. The higher-resolution $4 \mathrm{~km}$ precipitation data produced by MPE can be used to replace the traditional point or interpolated precipitation products in the development of these indices to provide a more detailed characterization of drought patterns. This holds the potential to advance local-scale drought monitoring activities as prioritized by NIDIS, as well as improve current state-of-the-art monitoring tools such as the USDM, which was initially designed to classify broadscale, national drought patterns but is increased being relied upon for county and subcounty drought information. With the goal of improved drought monitoring, Texas A\&M University, North Carolina State University, and Purdue University received a USDA award to improve the long-term calibration of the AHPS MPE analyses, and take the SPI products beyond Texas to include at least the eastern parts of the United States (i.e., south-central and eastern sections). The project began in January 2011, with tangible results expected a few months after that.

\section{ACKNOWLEDGMENT}

The views expressed are those of the author of this chapter and do not necessarily represent those of NOAA or the NWS. 


\section{REFERENCES}

Baeck, M. and J. Smith. 1998. Rainfall estimation by the WSR-88D for heavy rainfall events. Weather Forecasting 13:416-436.

Barker, T., P. Felsch, T. Mathewson, C. Sullivan, and M. Zenner. 2000. Test of the WSR-88D snow accumulation algorithm at Weather Field Office Missoula. Technical Attachment, NWS Western Region 00-13:1-6.

Boettcher, J. 2006. PPS parameters \& their impact on rainfall estimates. NEXRAD Now Newsletter 16:9-11.

Brown, J.F., B.D. Wardlow, T. Tadesse, M.J. Hayes, and B.C. Reed. 2008. The vegetation drought response index (VegDRI): A new integrated approach for monitoring drought stress in vegetation. GIScience and Remote Sensing 45(1):16-46.

Chrisman, J. and C. Chrisman. 1999. An operational guide to WSR-88D reflectivity data quality assurance. WSR-88D Radar Operations Center paper. http://www.roc.noaa. gov/WSR88D/PublicDocs/Publications/Reflectivity_Quality_Assurance.pdf (accessed December 13, 2011).

Chrisman, J.N., D. Rinderknecht, and R. Hamilton. 1995. WSR-88D clutter suppression and its impact on meteorological data interpretation. Preprints, First WSR$88 D$ User's Conference. WSR-88D Radar Operations Center, Norman, OK. http://www.roc.noaa.gov/WSR88D/PublicDocs/Publications/Legacy_Clutter_paper.pdf (accessed July 20, 2011).

Fournier, J. 1999. Reflectivity-rainfall rate relationships in operational meteorology. National Weather Service Technical Memo, National Weather Service, Tallahassee, FL.

Fulton, R., J. Breidenbach, D.-J. Seo, D. Miller, and T. O'Bannon. 1998. The WSR-88D rainfall algorithm. Weather Forecasting 13:377-395.

Gibson, W.P., C. Daly, T. Kittel, D. Nychka, C. Johns, N. Rosenbloom, A. McNab, and G. Taylor. 2002. Development of a 103-year high-resolution climate data set for the conterminous United States. Reprints, 13th AMS Conference on Applied Climatology, American Meteorological Society, Portland, OR, pp. 181-183.

Hunter, S. 1996. WSR-88D radar rainfall estimation: Capabilities, limitations and potential improvements. National Weather Association Digest 20(4):26-36.

Krajewski, W., G. Villarini, and J. Smith. 2010. Radar-rainfall uncertainties: Where are we after thirty years of effort? Bulletin of the American Meteorological Society 91:87-94.

Linsley, R., M. Kohler, and J. Paulhus. 1982. Hydrology for Engineers. 3rd edn, pp. 55-61. New York, McGraw-Hill.

Maddox, A. 2010. The importance of proper clutter filtering. NEXRAD Now Newsletter 19:8-12.

Nielsen-Gammon, J. and B. McRoberts. 2009. Tracking drought in Texas: Kicking it down a notch. Sixth US Drought Monitor Forum, Austin, TX. http://atmo.tamu.edu/osc/library/osc-pubs/drought_products.pdf (accessed December 13, 2011).

NWS/OHD/HL. 2010. MPE Editor User's Guide, Build 9.2. NWS/OHD Hydrologic Laboratory, Silver Spring, MD.

NWS/ROC. 1999. WSR-88D Interactive Training Modules: Volume 5; Build 10 WSR-88D Products. NWS/ROC Operations Training Branch, Norman, OK, CD-ROM.

O'Bannon, T. 1997. Using a 'terrain-based' hybrid scan to improve WSR-88D precipitation estimates. Preprints, 28th Conference on Radar Meteorology, Austin, TX, pp. 506-507. American Meteorological Society, Boston, MA.

Pereira Fo, A., K. Crawford, and C. Hartzell. 1988. Improving WSR-88D hourly rainfall estimates. Weather Forecasting 13:1016-1028.

Ryzhkov, A. and D. Zrnic. 1995. Precipitation and attenuation measurements at a $10 \mathrm{~cm}$ wavelength. Journal of Applied Meteorology 35:2121-2134. 
Scofield, R.A. and R.J. Kuligowski. 2003. Status and outlook of operational satellite precipitation algorithms for extreme-precipitation events. Weather Forecasting 18:1037-1051.

Seo, D.-J. 1999. Real-time estimation of rainfall fields using radar rainfall and rain gauge data. Journal of Hydrology 208:37-52.

Seo, D.-J. and J. Breidenbach. 2002. Real-time correction of spatially nonuniform bias in radar rainfall data using rain gauge measurements. Journal of Hydrometeorology 3:93-111.

Seo, D.-J., J. Breidenbach, and E. Johnson. 1999. Real-time estimation of mean field bias in radar rainfall data. Journal of Hydrology 223:131-147.

Story, G. 1996. The use of the hourly digital precipitation array at the West Gulf River Forecast Center. NWS/WGRFC, Fort Worth, TX, p. 15.

Story, G. 2000. Determining WSR-88D precipitation algorithm performance using the Stage III precipitation processing system. NWA Electronic Journal of Operational Meteorology, FTT2. http://www.nwas.org/ej/2000/2000.php (accessed July 20, 2011).

Vasiloff, S. 2001. WSR-88D performance in northern Utah during the winter of 1998-1999. Part 1: Adjustments to precipitation estimates. National Weather Service Technical Attachment, National Weather Service Western Region 01-02:1-7.

Vieux, B. and P. Bedient. 1998. Estimation of rainfall for flood prediction from WSR-88D reflectivity: A case study, 17-18 October 1994. Weather Forecasting 13:407-415.

Wilson, J. and E. Brandes. 1979. Radar measurement of rainfall: A summary. Bulletin of the American Meteorological Society 60:1048-1058.

Zrnic, D. and A. Ryzhkov. 1999. Polarimetry for weather surveillance radars. Bulletin of the American Meteorological Society 80:389-406. 


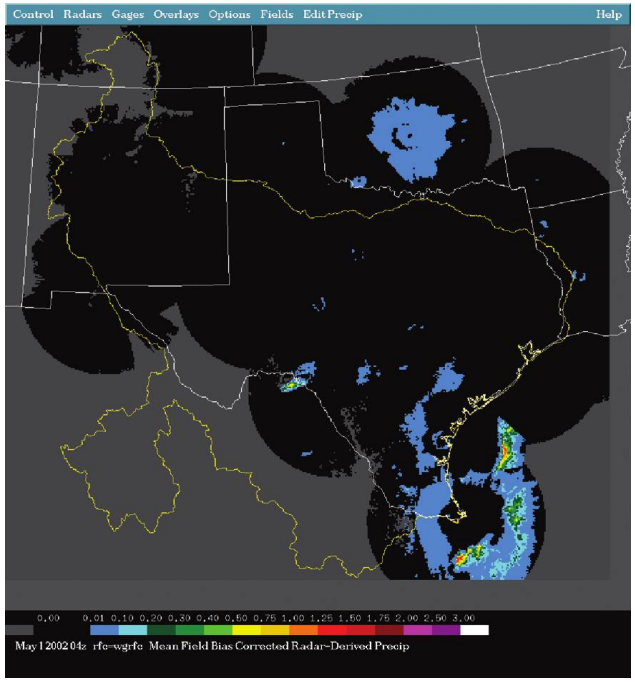

FIGURE 12.3 Widespread false precipitation, or AP, shown on the MPE radar mosaic. (Photos courtesy NOAA/NWS, Silver Spring, MD.)

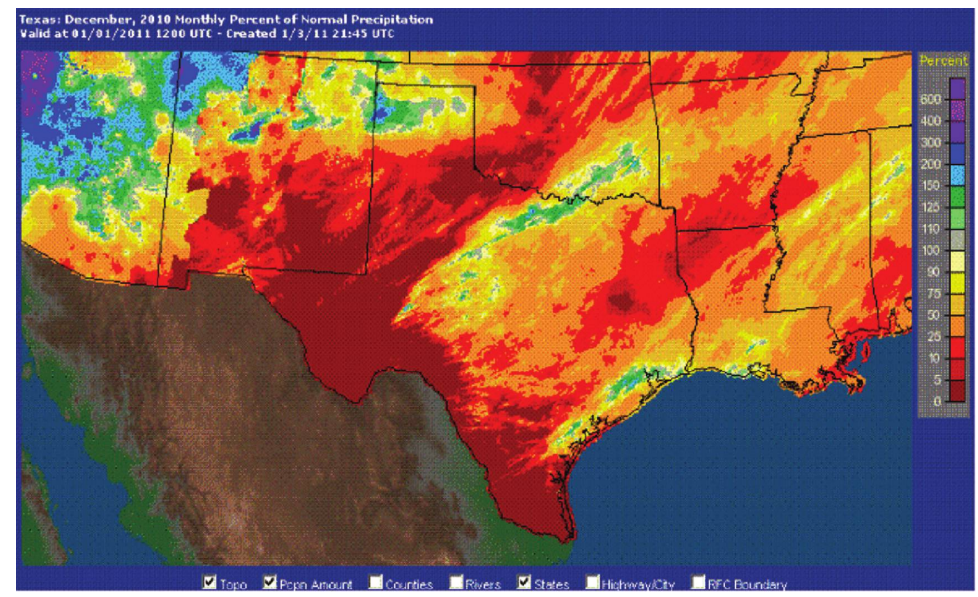

FIGURE 12.5 Percent of normal rainfall for the southern United States from the AHPS precipitation analysis page for December 2010. (Image courtesy of NOAA/NWS, Silver Spring, MD.) 


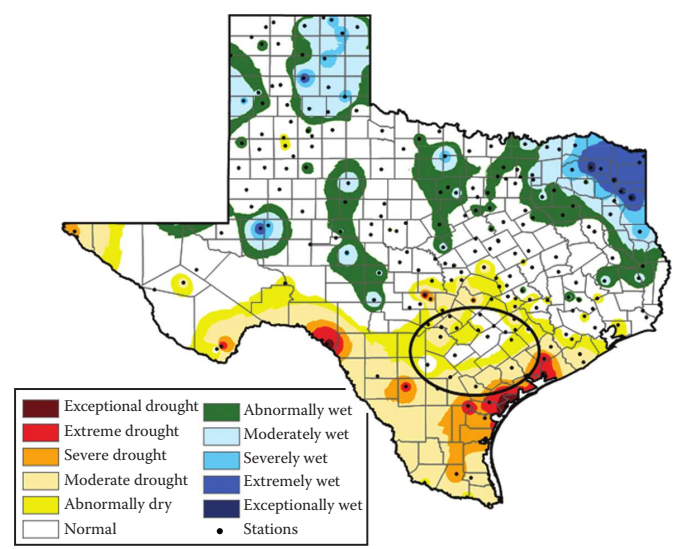

(a)

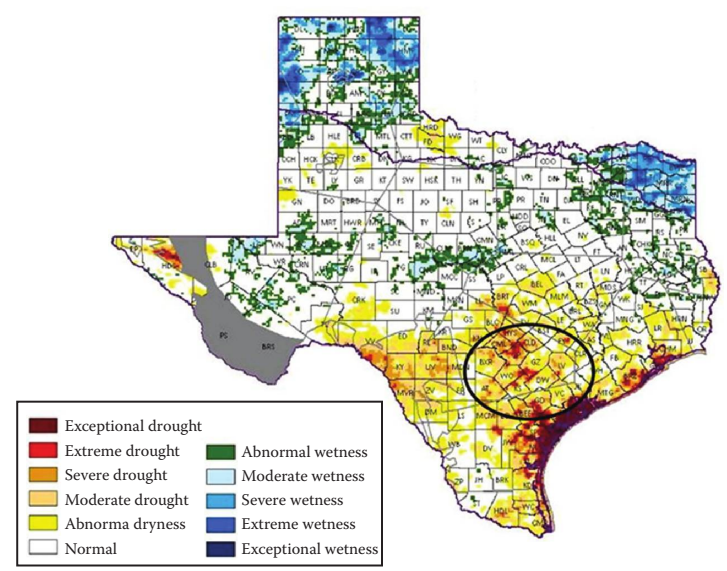

(b)

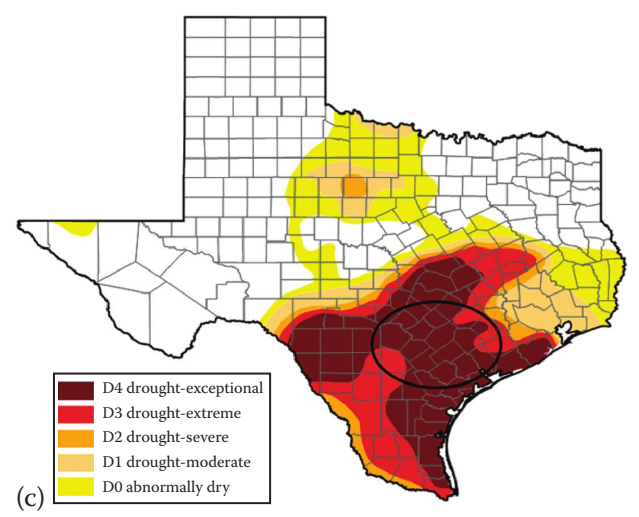

FIGURE 12.6 An 8 week SPI map interpolated from station-based precipitation data (a) and an 8 week SPI map derived from $4 \mathrm{~km}$ precipitation from MPE (b) (Image courtesy of Dr. John Nielsen-Gammon) for early September 2009 during the severe drought in southern Texas, as shown by the USDM map on September 7, 2009 (c). The circle highlights an area of exceptional drought in the USDM that is shown to have near-normal conditions in the interpolated SPI map (a) but clearly had localized areas of severe drought conditions that were detected in the SPI map based on higher-resolution, radar-based precipitation observations (b). 